\title{
Down Syndrome B-Lymphocyte Subpopulations, Intrinsic Defect or Decreased T-Lymphocyte Help
}

\author{
RUUD H. J. VERSTEGEN, MAAIKE A. A. KUSTERS, EUGENIE F. A. GEMEN, AND ESTHER DE VRIES
}

Departments of Pediatrics [R.H.J.V., M.A.A.K., E.d.V.] and Clinical Chemistry and Hematology [E.F.A.G.], Jeroen Bosch Hospital, 5200 ME 's-Hertogenbosch, The Netherlands

\begin{abstract}
Down syndrome (DS) is known for increased incidence of respiratory infections and autoimmune diseases, indicating impaired immunity. Until now, attention has been mainly focused on T lymphocytes. Therefore, we determined B-lymphocyte subpopulations in 95 children with DS compared with 33 age-matched control (AMC) children. DS serum immunoglobulin levels were compared with 962 non-DS children with recurrent infections. The results were combined with clinical data. Transitional and naive B lymphocytes are profoundly decreased in the children with DS. This could be caused by an intrinsic B-lymphocyte defect resulting in (partial) failure of B-lymphocyte generation, decreased antigen-induced proliferation and/or increased apoptosis, or by decreased proliferation due to deficient T-lymphocyte help, or a combination of these. The decreased $\mathrm{CD} 27^{+}, \mathrm{CD} 21^{\mathrm{high}}$, and $\mathrm{CD} 23^{+}$cells are reminiscent of common variable immunodeficiency and suggestive of disturbed peripheral B-lymphocyte maturation. Immunoglobulin levels in DS are abnormal-as has been described before-and different from non-DS children with recurrent infections. We conclude that the humoral immune system is abnormal in DS, but could not find a relation between B-lymphocyte subsets, immunoglobulins and clinical features of the children with DS in our cohort, nor could we answer the question whether DS lymphocytes are truly intrinsically deficient, or could all findings be explained by deficient $\mathrm{T}$ lymphocyte help. (Pediatr Res 67: 563-569, 2010)
\end{abstract}

$\mathrm{D}$ own syndrome (DS) is associated with recurrent-mainly respiratory-infections $(1,2)$, decreased responses to vaccination (3-8), a higher frequency of hepatitis B surface antigen carriers (3), and autoimmune diseases such as celiac disease and hypothyroidism (9-11). These features are suggestive of immunodeficiency. Until now, medical attention has been mainly focused on the thymic alterations and decreased absolute numbers of $\mathrm{T}$ lymphocytes in peripheral blood $(12,13)$. We recently showed that a striking B lymphocytopenia is present from the very beginning in patients with DS (14). This B lymphocytopenia could be due to an intrinsic B-lymphocyte defect, a deficient T-lymphocyte help, or a combination of these. An intrinsic B-lymphocyte defect could be due to (partial) failure of B-lymphocyte generation, decreased antigen-induced proliferation, and/or increased apoptosis. Deficient T-lymphocyte help could lead to disturbed B-lymphocyte activation and proliferation. Despite the B lym-

Received June 22, 2009; accepted January 4, 2010.

Correspondence: Esther de Vries, M.D., Ph.D., Department of Pediatrics, Jeroen Bosch Hospital (loc GZG), PO Box 90153, 5200 ME 's-Hertogenbosch, The Netherlands; e-mail: esid@estherdevries.nl; e.d.vries@jbz.nl

Supported financially by the JBZ Research Fund and the Irene Foundation. phocytopenia, a considerable hypergammaglobulinemia of $\operatorname{IgA}$ and $\mathrm{IgG}$ after the age of $5 \mathrm{y}$, with high levels of $\mathrm{IgG}_{1}$ and $\mathrm{IgG}_{3}$ and low levels of $\mathrm{IgG}_{2}$ and $\mathrm{IgG}_{4}$, is described $(3,15,16)$.

This combination of profound $\mathrm{B}$ lymphocytopenia and hypergammaglobulinemia favors a disturbance in T-lymphocyte help, with the possibility that immunoglobulins are oligoclonal in DS, and specific T-cell-dependent antibody responses inadequate. The latter has indeed been described $(3,15)$. However, the T-cell-independent antibody response to pneumococcal polysaccharide antigen is also decreased in DS (4), suggesting an intrinsic B-lymphocyte defect is also present. We studied B-lymphocyte subpopulations in relation to relevant clinical features in 95 children with DS, to further unravel this question.

\section{METHODS}

Study population. From 95 noninstitutionalized children with DS (49 boys; Fig. 1), either visiting the Jeroen Bosch Hospital, 's-Hertogenbosch or the Rijnstate Hospital, Arnhem, the Netherlands, an extra $3 \mathrm{~mL}$ of EDTA and $7 \mathrm{~mL}$ of blood without additive was drawn during routine follow-up of thyroid function after parental informed consent. All children were otherwise healthy at the time of sampling. Leftover EDTA blood from 33 healthy age-matched control (AMC) children who underwent venipuncture, e.g. preoperative screening for minor surgery, was used as control.

We retrospectively collected the titers of serum $\operatorname{IgG}, \operatorname{IgA}$, and $\operatorname{IgM}$ that were determined for diagnostic purposes in 962 non-DS patients suffering from recurrent infections (younger than 21 y) between January 2006 and July 2008 in the Jeroen Bosch Hospital, 's-Hertogenbosch, and the Bernhoven Hospital, Oss/Veghel, The Netherlands. In 285 of the 962 patients, IgGsubclasses were also determined. The study was approved by the local Medical Ethics Committees of both hospitals.

Immunophenotyping. Three-color flow cytometric immunophenotyping was performed to determine B-lymphocyte subpopulations in children with both DS and AMC using the lysed whole-blood method. FITC, phycoerythrin (PE), and PE-cyanine 5 (PE-Cy5)-conjugated antibodies were used with the following antigen specificity: CD3 (PE-Cy5; Immunotech, Marseille, France), CD5 [FITC; Becton Dickinson (BD), San Jose, CA], CD10 (FITC; BD), CD16/CD56 (FITC; BD), CD14 (PE; BD), CD15 (FITC; IQProducts, Groningen, The Netherlands), CD19 (PE-Cy5; Immunotech), CD20 (PE; BD), CD21 (PE; BD), CD23 (PE; BD), CD27 (FITC; $\mathrm{BD}), \mathrm{CD} 38$ (PE; BD), CD45 (PE-Cy5; Immunotech), $\kappa$ (PE; Dako, Carpinteria, $\mathrm{CA})$, and $\lambda$ (PE; Dako). In all children, $\mathrm{T}$ lymphocytes $\left(\mathrm{CD}^{+}\right)$, B lymphocytes $\left(\mathrm{CD} 19^{+}\right)$, natural killer $(\mathrm{NK})$ cells $\left(\mathrm{CD} 16^{+}\right.$and/or $\left.\mathrm{CD}_{56}{ }^{+} \mathrm{CD} 3^{-}\right)$, and $\mathrm{CD} 21$ and CD5 expression on CD $19^{+} \mathrm{B}$ lymphocytes were determined. An extended protocol was used in the last 55 included children. In this group, CD10, $\kappa$ and $\lambda$ expression, CD27 and CD20 expression, CD27 and CD38 expression, and CD27 and CD23 expression on $\mathrm{CD} 19^{+}$B lymphocytes were also analyzed.

\footnotetext{
Abbreviations: AMC, age-matched control; BD, Becton Dickinson; DS, Down syndrome; NK, natural killer; PE, phycoerythrin; PE-Cy5, PEcyanine 5
} 


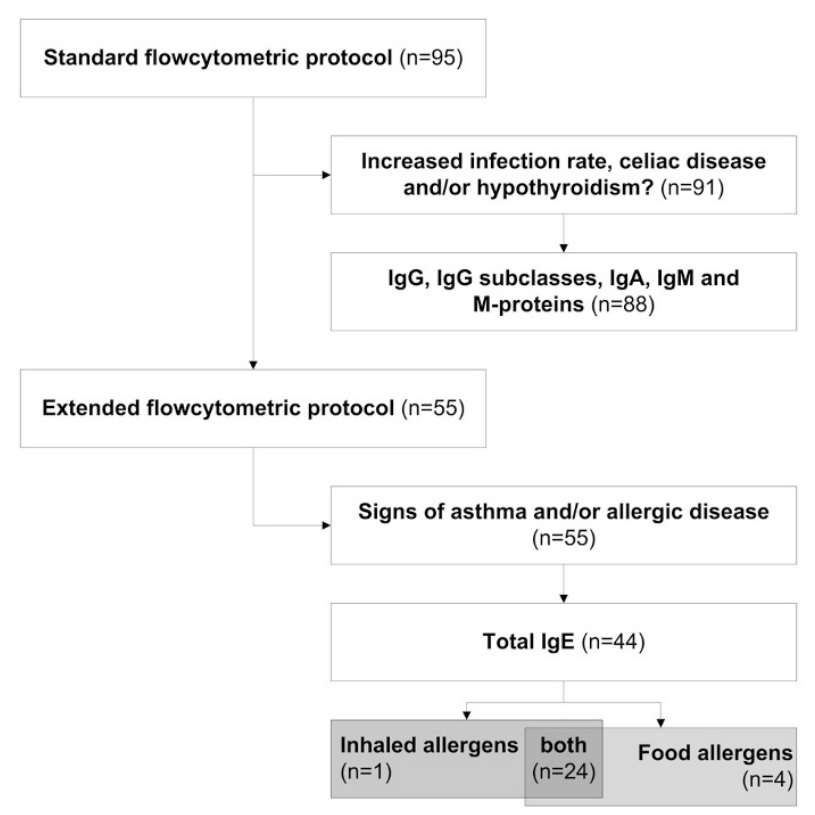

Figure 1. Patient flow diagram. Flow diagram showing group size of patients with Down syndrome in relation to assessed variables.

Aliquots were incubated for $15 \mathrm{~min}$ at room temperature in the dark with different combinations of optimally titrated antibodies. Only for the samples that were incubated with anti- $\kappa$ or anti- $\lambda$ antibodies, the aliquots were washed three times with $0.5 \%$ BSA/PBS before incubation. Erythrocytes were lysed using FACSLysing solution (BD) according to the manufacturer's protocol. The remaining cells were washed twice with BSA/PBS and analyzed by flow cytometry after calibration with the SPHERO CaliFlow kit (Spherotech, Libertyville, IL) as recommended by the European Society for Clinical Cell Analysis (17). A FACScan or FACSCalibur flow cytometer (BD) was used in combination with CellQuest or CellQuest Pro software (BD). The lymphocyte gate was checked with a CD15/CD14/CD45 triple labeling and considered correct if $<5 \%$ contamination was present. T lymphocytes and NK cells were used to check whether the "lymphosum" (B + T + NK) equaled $100 \pm 5 \%$. Absolute leukocyte counts were determined with a Sysmex SE-9500 hematology analyzer (Sysmex, Kobe, Japan). Absolute numbers of B-lymphocyte subpopulations were calculated by multiplying the absolute leukocyte count $\left(\times 10^{9} / \mathrm{L}\right)$ by the relative total lymphocyte size $(\%)$ and relative size of the lymphocyte subpopulation (\%).

Immunoglobulins. For 88 of the 95 children with DS, serum IgG, IgG1, $\mathrm{IgG} 2, \mathrm{IgG} 3$, IgG4, IgA, and IgM were studied; in seven children, serum was not available. $\operatorname{IgG}, \operatorname{IgA}$, and $\operatorname{IgM}$ were determined by kinetic nephelometry (Beckman Coulter Array 360, Beckman Coulter, Fullerton, CA); IgGsubclasses were assessed by kinetic nephelometry using a human IgG subclass nephelometry kit (Sanquin Reagents, Amsterdam, The Netherlands).

Qualitative M-proteins were assessed by serum electrophoresis on alkaline-buffered ( $\mathrm{pH}$ 9.2) agarose gels by a Hydrasys system (Sebia, Norcross, GA). In cases of uncertainty, additional serum electrophoresis using immunofixation with monovalent antiserum was performed.

$\operatorname{IgE}$ was measured in 44 of the 55 children included in the extended protocol using a sandwich chemiluminescent immunoassay (Immulite 2500; DPC/Siemens, Deerfield, IL); the volume of serum available was insufficient in 11 children. Specific IgE testing (Immulite 2500) of food and inhaled allergens was performed in 28 and 25 children, respectively. When insufficient serum was available, we tested for food allergens only for children aged younger than $2 \mathrm{y}$ and inhaled allergens only for children aged older than $2 \mathrm{y}$. The Fp5 food allergen panel (DPC/Siemens) contained egg white, cow's milk, codfish, soya, peanut, and wheat allergen. The AlaTOP inhaled allergen panel (DPC/Siemens) contained house mite (Dermatophagoides pteronyssinus), cat dander epithelium, dog dander, Bermuda grass, timothy grass, Penicillium notatum, Alternaria tenuis, birch, Japanese cedar, common ragweed (Ambrosia artemisiifolia), and English plantain and Parietaria officinalis allergen. To interpret the IgE results, we used our laboratory cutoff values of $<50 \mathrm{U} / \mathrm{mL}$ for children aged younger than $10 \mathrm{y}$ and $<90 \mathrm{U} / \mathrm{mL}$ for children aged older than $10 \mathrm{y}$ and adults.

Review of medical files. The medical files of 91 of the 95 children with DS were reviewed retrospectively; four files were unavailable. The 91 children were divided into four groups: 1) no increased infection rate, 2) increased infection rate (age at inclusion younger than 8 y), 3) increased infection rate (age at inclusion older than $8 \mathrm{y}$ ), and 4) increased infection rate until, but not after, the age of $8 \mathrm{y}$. The presence of celiac disease or autoimmune hypothyroidism was noted. In addition, the 55 patients of the extended protocol were also divided into positive or negative for symptoms of asthma and/or allergic disease (recurrent cough, persistent wheeze, admission on a pediatric ward for asthma exacerbation, clinical response to bronchodilators and/or inhalation corticosteroids, and clinical signs of allergic disease).

Statistical analysis. An analysis of variance (completely randomized two-factorial design; $p<0.05$ ) was applied to the data. For this analysis, we excluded those age groups for which the number of AMC data was too low. The two fixed factors in the analysis of variance were age (three age groups: 2-5, 5-10, and 10-16 y) and the difference between DS and AMC children. Levene's test for equality of error variances was used, and the results are mentioned in the text only when $p<0.05$. The one sample $t$ test $(p<0.05)$ was used to compare the Ig values of children with DS and non-DS children suffering from recurrent infections with the mean of age-matched reference values and each other $(18,19)$. All analyses were performed with SPSS 16.0 for Windows.

\section{RESULTS}

B-lymphocyte subpopulations. The absolute and relative numbers of CD19 ${ }^{+}$B-lymphocyte subpopulations with results of statistical analyses can be found in Table 1, clinically relevant data are presented in Table 2. We did not find a relation between any of the determined B-lymphocyte subpopulations and the incidence of infections or of allergic complaints and/or asthma in these children with DS. The values for $\mathrm{CD} 19^{+} \mathrm{B}$ lymphocytes were reported before (14): the $\mathrm{CD} 19^{+} \mathrm{B}$-lymphocyte count is decreased significantly in all age groups in DS compared with AMC, and the enormous expansion, which is found in healthy children in the first years of life, is lacking (20). The effect of age on the CD19 ${ }^{+}$ B-lymphocyte count is significantly different between DS and AMC children (interaction for absolute values; Table 1), so this finding is highly significant. The $\kappa / \lambda$ ratio is slightly increased in older children with DS. $\mathrm{CD}^{+}$and $\mathrm{CD}^{-} \mathrm{B}$ lymphocytes follow the pattern of total $\mathrm{CD} 19^{+} \mathrm{B}$ lymphocytes in children with DS. There is no evident increase of "immature" B lymphocytes in DS: CD $10^{+}$and CD20 ${ }^{-}$B lymphocytes do not clearly differ between DS and AMC children.

$\mathrm{CD} 27^{-} \mathrm{CD} 38^{\mathrm{dim}}$ naive B lymphocytes and $\mathrm{CD} 27^{-} \mathrm{CD} 38^{+}$ transitional B lymphocytes follow the pattern of total CD19 ${ }^{+}$ B lymphocytes in DS as well. Unfortunately, we cannot differentiate between $\mathrm{CD} 27^{+} \mathrm{CD} 38^{\mathrm{dim}} \mathrm{IgD}^{+}$marginal zone and $\mathrm{CD} 27^{+} \mathrm{CD} 38^{\mathrm{dim}} \mathrm{IgD}{ }^{-}$memory B lymphocytes because the expression of $\mathrm{IgD}$ was not determined. Absolute and relative numbers of total $\mathrm{CD} 27^{+}$B lymphocytes are decreased in DS compared with AMC children; the absolute numbers show a slight increase during the $\mathrm{CD} 19^{+} \mathrm{B}$-lymphocyte expansion in the first years of life, which is less prominent in DS than in AMC children. The $\mathrm{CD} 27^{+} \mathrm{CD} 38^{++}$plasma cell population is small in peripheral blood, but-unexpectedly — not different between DS and AMC children. The relative and absolute numbers of B lymphocytes with high expression of CD21 $\left(\mathrm{CD} 21^{\text {high }}\right)$ are significantly decreased in children with DS; the absolute numbers decline with age, but more so in AMC than in children with DS due to a higher initial peak in the former. The same holds true for CD23. The relative expression of CD23 within the $\mathrm{CD} 19^{+}$B-lymphocyte population shows a far wider range in DS than in AMC children. 


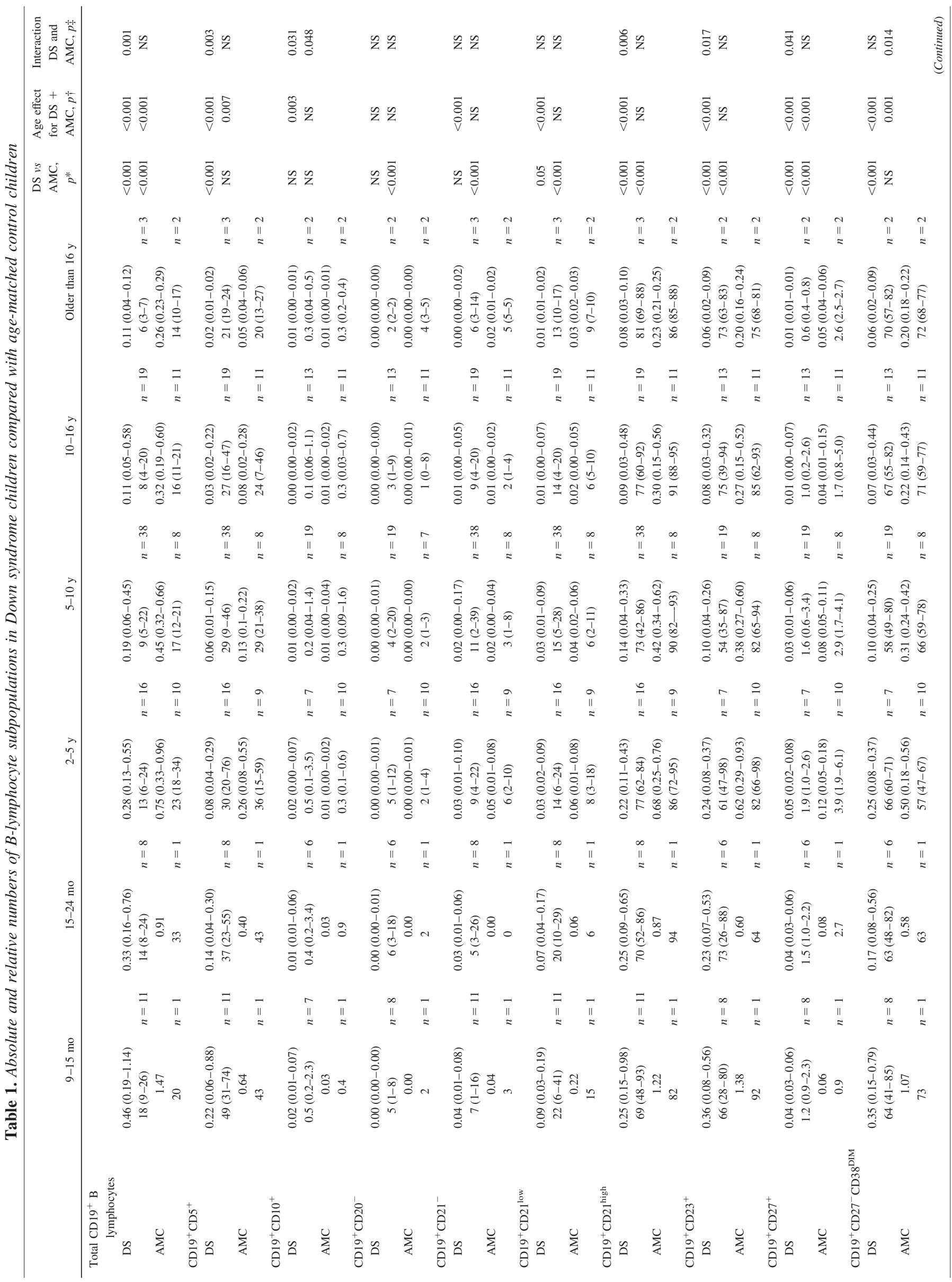




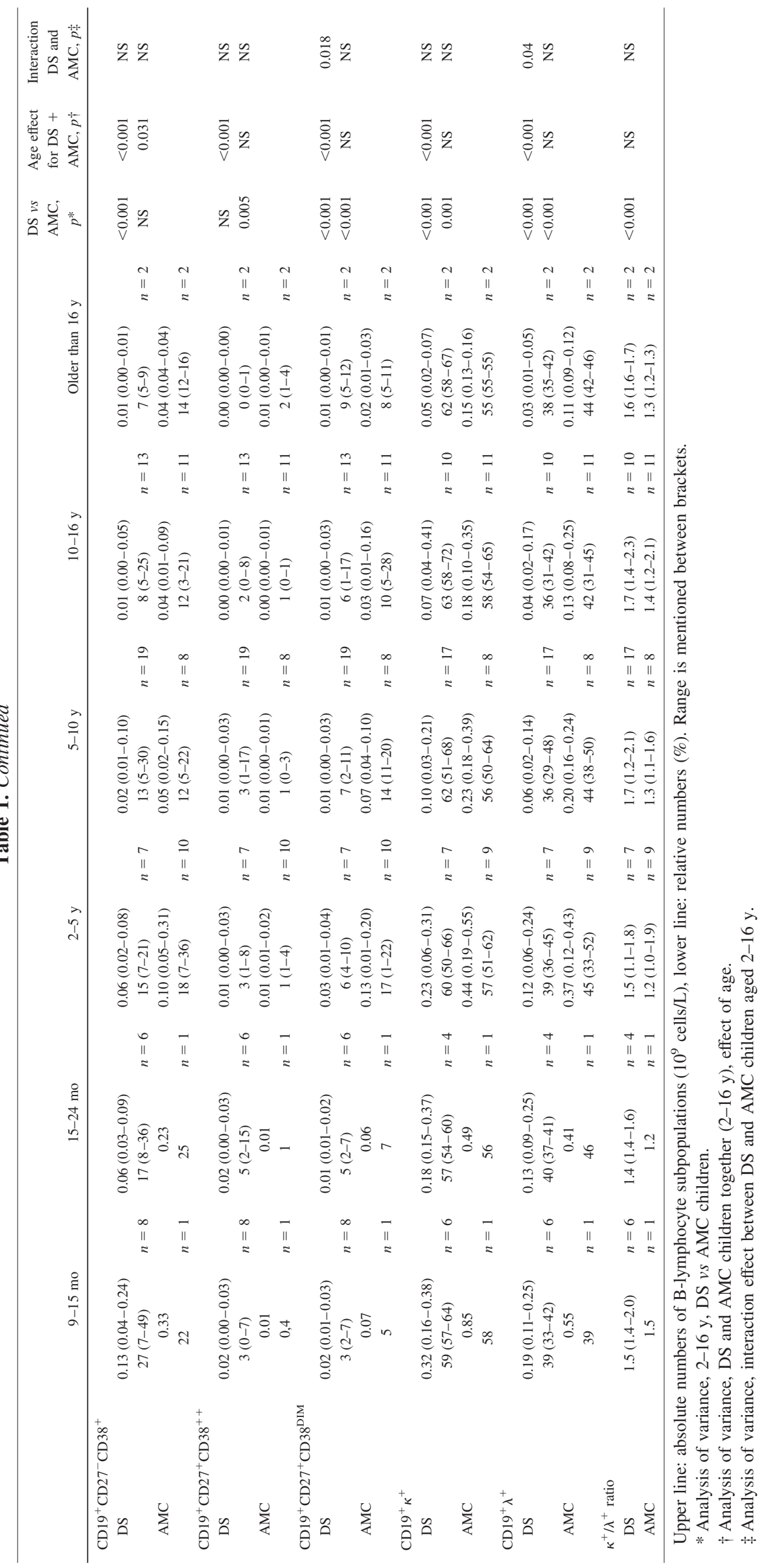


Table 2. Clinical features

\begin{tabular}{|c|c|c|c|c|c|c|c|}
\hline & $\begin{array}{l}9-15 \text { mo } \\
(n=11)\end{array}$ & $\begin{array}{c}15-24 \text { mo } \\
(n=4)\end{array}$ & $\begin{array}{c}2-5 \mathrm{y} \\
(n=16)\end{array}$ & $\begin{array}{l}5-10 y \\
(n=38)\end{array}$ & $\begin{array}{l}10-16 y \\
(n=19)\end{array}$ & $\begin{array}{l}\text { Older than } 16 \mathrm{y} \\
(n=3)\end{array}$ & $\begin{array}{l}\text { Total } \\
(n=91)\end{array}$ \\
\hline $\begin{array}{l}\text { No increased infection rate (all } \\
\text { ages) }\end{array}$ & $n=5$ & & $n=6$ & $n=5$ & $n=1$ & $n=2$ & $n=19$ \\
\hline $\begin{array}{l}\text { Increased-mainly respiratory-infection } \\
\text { rate (age at inclusion } \\
\text { younger than } 8 \mathrm{y})\end{array}$ & $n=6$ & $n=4$ & $n=10$ & $n=20$ & & & $n=40$ \\
\hline $\begin{array}{l}\text { Increased-mainly respiratory-infection } \\
\text { rate until, but not after, } \\
\text { the age of } 8 \text { years }\end{array}$ & & & & $n=6$ & $n=12$ & $n=0$ & $n=18$ \\
\hline $\begin{array}{l}\text { Increased-mainly respiratory-infection } \\
\text { rate (age at inclusion } \\
\text { older than } 8 \mathrm{y} \text { ) }\end{array}$ & & & & $n=7$ & $n=6$ & $n=1$ & $n=14$ \\
\hline Celiac disease & $0 / 11^{*}$ & $1 / 4$ & $1 / 16$ & $2 / 38$ & $1 / 19$ & $0 / 3$ & $5 / 91$ \\
\hline \multirow[t]{2}{*}{ Autoimmune hypothyroidism } & $0 / 11$ & $1 / 4$ & $0 / 16$ & $1 / 38$ & $1 / 19$ & $0 / 3$ & $3 / 91$ \\
\hline & $\begin{array}{l}9-15 \text { mo } \\
(n=8)\end{array}$ & $\begin{array}{c}15-24 \text { mo } \\
(n=6)\end{array}$ & $\begin{array}{l}2-5 \mathrm{y} \\
(n=7)\end{array}$ & $\begin{array}{l}5-10 y \\
(n=19)\end{array}$ & $\begin{array}{l}10-16 y \\
(n=13)\end{array}$ & $\begin{array}{l}\text { Older than } 16 \mathrm{y} \\
\quad(n=2)\end{array}$ & $\begin{array}{c}\text { Total } \\
(n=55)\end{array}$ \\
\hline Asthma & $4 / 8 \dagger$ & $3 / 6 \dagger$ & $0 / 7$ & $3 / 19$ & $0 / 13$ & $0 / 2$ & $10 / 55$ \\
\hline Allergy & $1 / 8$ & $1 / 6$ & $0 / 7$ & $0 / 19$ & $0 / 13$ & $0 / 2$ & $2 / 55$ \\
\hline Total IgE increased & $0 / 6$ & $1 / 3$ & $1 / 5$ & $2 / 17$ & $2 / 12$ & $0 / 1$ & $6 / 44$ \\
\hline $\begin{array}{l}\text { Specific IgE inhaled allergens } \\
\text { present }\end{array}$ & $0 / 2$ & $0 / 0$ & $0 / 3$ & $0 / 12$ & $0 / 7$ & $0 / 1$ & $0 / 25$ \\
\hline Specific IgE food allergens present & $0 / 3$ & $0 / 2$ & $0 / 4$ & $0 / 12$ & $0 / 6$ & $0 / 1$ & $0 / 28$ \\
\hline
\end{tabular}

* 0/11 means 0 of 11 patients tested, etc.

$\dagger$ It is doubtful whether these children will continue to have the diagnosis of asthma in later years (21).


Figure 2. Immunoglobulin values in Down syndrome compared with reference values and children suffering from recurrent infections. Values of a) IgG, b) IgA, c) $\mathrm{IgM}$, d) $\mathrm{IgG}_{1}$, e) $\mathrm{IgG}_{2}$, f) $\mathrm{IgG}_{3}$, and g) $\mathrm{IgG}_{4}$ obtained in 88 children with DS are shown as black dots. $x$ axis age in mo; $y$ axis immunoglobulin levels (g/L). The gray areas represent the values between the $\mathrm{p} 2.5$ and $\mathrm{p} 97.5$ of the determined immunoglobulin levels per age group in patients suffering from recurrent infections. Age-matched reference values (p2.5 and p97.5) are shown as a black line.

Immunoglobulins. The serum levels of $\operatorname{IgG}, \mathrm{IgG}_{1}, \mathrm{IgG}_{2}$, $\mathrm{IgG}_{3}, \mathrm{IgG}_{4}, \mathrm{IgA}$, and $\mathrm{IgM}$ found in the children with $\mathrm{DS}$ and in non-DS children with increased infection rates (see Methods section) in comparison with age-matched reference values are shown in Figure $2(18,19)$. In the DS group, mean IgG and $\mathrm{IgG}_{1}$ are already higher than the age-matched reference values from the ages of 2 and 3 y onwards, respectively (one-sample $t$ test; $p<0,05$ ). Mean IgA and $\operatorname{IgG}_{3}$ are normally distributed, but mean $\operatorname{IgM}$ and $\operatorname{IgG}_{2}$ are lower in children with DS in all age groups. $\operatorname{IgG}_{4}$ values are consistently very low in children with DS. Mean Ig serum levels in the non-DS children with increased infection rates are similar to the children with DS for $\mathrm{IgA}$ and $\mathrm{IgG}_{2}$, but mean $\mathrm{IgG}$ is higher in DS children in some of the older age groups, and mean $\operatorname{IgG}_{1}$ and $\mathrm{IgG}_{3}$ are higher in DS children from the ages of 3 and 2 y onwards, respectively. Mean $\operatorname{IgM}$ and $\operatorname{IgG}_{4}$ are lower in children with 
DS than in the non-DS children with increased infection rates in the older age groups. We did not find any mono- or oligoclonal M-proteins in the 88 children with DS tested. IgE is increased in six of the 44 DS children tested; five showed high relative percentages of $\mathrm{CD} 23^{+} \mathrm{B}$ lymphocytes, which are within the range of the AMC group (one with asthma; data not shown). Specific IgE testing of food and inhaled allergens is negative in all children tested.

\section{DISCUSSION}

The profound B-lymphocytopenia in DS children, with decreased transitional and naive B lymphocytes compared with AMC children, is the most striking result of our study. There are no indications for release of unusual numbers of "immature" B lymphocytes from the bone marrow $\left(\mathrm{CD} 10^{+}\right.$, $\mathrm{CD} 20^{-}$), the cells show the normal phenotype of the transitional and naive stages of peripheral B-lymphocyte development (22). As stated before, this could be caused by decreased B-lymphocyte proliferation due to a disturbance in $\mathrm{T}$ lymphocyte help, an intrinsic B-lymphocyte defect, or a combination of these.

Interestingly, the distribution of B-lymphocyte subpopulations is reminiscent of the situation found in patients with common variable immunodeficiency (CVID)(23-25): $\mathrm{CD}_{2}{ }^{+}$ cells, CD2 $1^{\text {high }}$ cells, and $\mathrm{CD} 23^{+}$cells are decreased in absolute and relative numbers in the children with DS. These findings are suggestive of an intrinsic defect in B-lymphocyte maturation in the periphery.

CD21 is the complement type 2 receptor; it has a role in the response to polysaccharide antigens such as pneumococcal capsular elements. These antigens form a complex with CD21 on B lymphocytes causing a T-cell-independent response. The lower response to unconjugated pneumococcal vaccination and the increased rate of respiratory infections in DS could be related to this decreased expression of CD21. Interestingly, a subgroup of patients with CVID with relatively increased CD $21^{\text {low }}$ B lymphocytes is more likely to develop splenomegaly, autoimmune diseases, and lower respiratory tract infections (26); the latter two are frequently found in DS as well.

CD23 is the low-affinity IgE-receptor (FceRII), it is a ligand of CD21. Together, they stimulate B-lymphocyte proliferation and differentiation (27). CD23 expression is increased just before the class switch from $\operatorname{IgM}$ to $\operatorname{IgG}, \operatorname{IgA}$, or $\operatorname{IgE}(27)$. Besides, CD23 is involved in both positive and negative feedback loops for IgE-homeostasis (27). Interestingly, both asthma incidence (RR: 0.4; 95\% CI: 0.2-0.6) and IgE-levels are decreased in DS $(28,29)$, which is consistent with our findings. Our results suggest that increased $\mathrm{IgE}$ production is associated with a higher level of CD23 expression in children with DS.

The serum Ig values in children with DS—-with or without recurrent infections-and non-DS children with recurrent infections are both abnormal but differ from each other. Decreased IgG2 is a well-known abnormality in children with recurrent infections; this coincides with our findings in children with DS. However, the increased IgG, IgG1, and IgG3 and decreased $\mathrm{IgM}$ and $\mathrm{IgG}_{4}$ levels are found in the children with DS only.

In conclusion, we found that the humoral immune system is disturbed in children with DS. We could not differentiate between an intrinsic B-lymphocyte defect and disturbed $\mathrm{T}$ lymphocyte help as the most important cause based on our present data. This question remains unanswered, and further studies are needed to solve it.

Acknowledgments. We thank patients and parents for their participation in this study and Mr. Jeroen Ooms for technical assistance in preparing Figure 2.

\section{REFERENCES}

1. Goldacre MJ, Wotton CJ, Seagroatt V, Yeates D 2004 Cancers and immune related diseases associated with Down's syndrome: a record linkage study. Arch Dis Child 89:1014-1017

2. Garrison MM, Jeffries H, Christakis DA 2005 Risk of death for children with down syndrome and sepsis. J Pediatr 147:748-752

3. Avanzini MA, Monafo V, De AM, Maccario R, Burgio GR, Plebani A, Ugazio AG, Hanson LA 1990 Humoral immunodeficiencies in Down syndrome: serum IgG subclass and antibody response to hepatitis B vaccine. Am J Med Genet Suppl 7:231-233

4. Costa-Carvalho BT, Martinez RM, Dias AT, Kubo CA, Barros-Nunes P, Leiva L, Sole D, Carneiro-Sampaio MM, Naspitz CK, Sorensen RU 2006 Antibody response to pneumococcal capsular polysaccharide vaccine in Down syndrome patients. Braz J Med Biol Res 39:1587-1592

5. Ferreira CT, Leite JC, Taniguchi A, Vieira SM, Pereira-Lima J, da Silveira TR 2004 Immunogenicity and safety of an inactivated hepatitis A vaccine in children with Down syndrome. J Pediatr Gastroenterol Nutr 39:337-340

6. Epstein LB, Philip R 1987 Abnormalities of the immune response to influenza antigen in Down syndrome (trisomy 21). Prog Clin Biol Res 246:163-182

7. Philip R, Berger AC, McManus NH, Warner NH, Peacock MA, Epstein LB 1986 Abnormalities of the in vitro cellular and humoral responses to tetanus and influenza antigens with concomitant numerical alterations in lymphocyte subsets in Down syndrome (trisomy 21). J Immunol 136:1661-1667

8. McKay E, Hems G, Massie A, Moffat MA, Phillips KM 1978 Serum antibody to poliovirus in patients in a mental deficiency hospital, with particular reference to Down's syndrome. J Hyg (Lond) 81:25-30

9. Karlsson B, Gustafsson J, Hedov G, Ivarsson SA, Anneren G 1998 Thyroid dysfunction in Down's syndrome: relation to age and thyroid autoimmunity. Arch Dis Child 79:242-245

10. Sanchez-Albisua I, Storm W, Wascher I, Stern M 2002 How frequent is coeliac disease in Down syndrome? Eur J Pediatr 161:683-684

11. Storm W 1990 Prevalence and diagnostic significance of gliadin antibodies in children with Down syndrome. Eur J Pediatr 149:833-834

12. Burgio GR, Lanzavecchia A, Maccario R, Vitiello A, Plebani A, Ugazio AG 1978 Immunodeficiency in Down's syndrome: T-lymphocyte subset imbalance in trisomic children. Clin Exp Immunol 33:298-301

13. Levin S, Schlesinger M, Handzel Z, Hahn T, Altman Y, Czernobilsky B, Boss J 1979 Thymic deficiency in Down's syndrome. Pediatrics 63:80-87

14. De Hingh YC, van der Vossen P, Gemen EF, Mulder AB, Hop WC, Brus F, de Vries E 2005 Intrinsic abnormalities of lymphocyte counts in children with down syndrome. J Pediatr 147:744-747

15. Burgio GR, Ugazio AG, Nespoli L, Marcioni AF, Bottelli AM, Pasquali F 1975 Derangements of immunoglobulin levels, phytohemagglutinin responsiveness and $\mathrm{T}$ and B cell markers in Down's syndrome at different ages. Eur J Immunol 5:600-603

16. Nespoli L, Burgio GR, Ugazio AG, Maccario R 1993 Immunological features of Down's syndrome: a review. J Intellect Disabil Res 37:543-551

17. Kraan J, Gratama JW, Keeney M, D'Hautcourt JL 2003 Setting up and calibration of a flow cytometer for multicolor immunophenotyping. J Biol Regul Homeost Agents 17:223-233

18. Jolliff CR, Cost KM, Stivrins PC, Grossman PP, Nolte CR, Franco SM, Fijan KJ, Fletcher LL, Shriner HC 1982 Reference intervals for serum IgG, IgA, IgM, C3, and C4 as determined by rate nephelometry. Clin Chem 28:126-128

19. Vlug A, Nieuwenhuys EJ, van Eijk RV, Geertzen HG, van Houte AJ 1994 Nephelometric measurements of human IgG subclasses and their reference ranges. Ann Biol Clin (Paris) 52:561-567

20. Comans-Bitter WM, de Groot R, van den Beemd R, Neijens HJ, Hop WC, Groeneveld K, Hooijkaas H, van Dongen JJ 1997 Immunophenotyping of blood lymphocytes in childhood. Reference values for lymphocyte subpopulations. J Pediatr 130:388-393

21. Martinez FD 2002 Development of wheezing disorders and asthma in preschool children. Pediatrics 109:362-367

22. Van Zelm MC, Szczepanski T, van der Burg M, van Dongen JJ 2007 Replication history of B lymphocytes reveals homeostatic proliferation and extensive antigeninduced B cell expansion. J Exp Med 204:645-655 
23. Warnatz K, Wehr C, Drager R, Schmidt S, Eibel H, Schlesier M, Peter HH 2002 Expansion of CD19(hi)CD21(lo/neg) B cells in common variable immunodeficiency (CVID) patients with autoimmune cytopenia. Immunobiology 206:502-513

24. Moratto D, Gulino AV, Fontana S, Mori L, Pirovano S, Soresina A, Meini A, Imberti L, Notarangelo LD, Plebani A, Badolato R 2006 Combined decrease of defined B and $\mathrm{T}$ cell subsets in a group of common variable immunodeficiency patients. Clin Immunol 121:203-214

25. Warnatz K, Denz A, Drager R, Braun M, Groth C, Wolff-Vorbeck G, Eibel H, Schlesier M, Peter HH 2002 Severe deficiency of switched memory B cells (CD27(+)IgM $(-) \operatorname{IgD}(-))$ in subgroups of patients with common variable immunodeficiency: a new approach to classify a heterogeneous disease. Blood 99:1544-1551

26. Wehr C, Kivioja T, Schmitt C, Ferry B, Witte T, Eren E, Vlkova M, Hernandez M, Detkova D, Bos PR, Poerksen G, von Bernuth H, Baumann U, Goldacker S,
Gutenberger S, Schlesier M, Bergeron-van der Cruyssen F, Le Garff M, Debre P, Jacobs R, Jones J, Bateman E, Litzman J, van Hagen PM, Plebani A, Schmidt RE, Thon V, Quinti I, Espanol T, Webster AD, Chapel H, Vihinen M, Oksenhendler E, Peter HH, Warnatz K 2008 The EUROclass trial: defining subgroups in common variable immunodeficiency. Blood 111:77-85

27. Gould HJ, Beavil RL, Reljic R, Shi J, Ma CW, Sutton BJ, Ghirlando R 1997 IgE homeostasis: is CD23 the safety switch? In: Vercelli D (ed) IgE Regulation: Molecular Mechanisms. John Wiley and Sons, New York, NY, pp 35-59

28. Forni GL, Rasore-Quartino A, Acutis MS, Strigini P 1990 Incidence of bronchial asthma in Down syndrome [Editorial comment]. J Pediatr 116:487

29. Lockitch G, Ferguson A 1990 Incidence of bronchial asthma in Down syndrome [Reply to editorial comment]. J Pediatr 116:487-488 